This item was submitted to Loughborough's Research Repository by the author.

Items in Figshare are protected by copyright, with all rights reserved, unless otherwise indicated.

\title{
Evaluating community-based integrated health and social care services: The Simtegr8 approach
}

PLEASE CITE THE PUBLISHED VERSION

https://doi.org/10.1109/WSC40007.2019.9004874

\section{PUBLISHER}

Institute of Electrical and Electronics Engineers (IEEE), Inc.

\section{VERSION}

AM (Accepted Manuscript)

\section{PUBLISHER STATEMENT}

Personal use of this material is permitted. Permission from IEEE must be obtained for all other uses, in any current or future media, including reprinting/republishing this material for advertising or promotional purposes, creating new collective works, for resale or redistribution to servers or lists, or reuse of any copyrighted component of this work in other works.

\section{LICENCE}

\section{All Rights Reserved}

\section{REPOSITORY RECORD}

Tako, Antuela, Stewart Robinson, Anastasia Gogi, Zoe Radnor, and Cheryl Davenport. 2020. "Evaluating Community-based Integrated Health and Social Care Services: The Simtegr8 Approach". figshare. https://hdl.handle.net/2134/10772876.v1. 


\title{
EVALUATING COMMUNITY-BASED INTEGRATED HEALTH AND SOCIAL CARE SERVICES: THE SIMTEGR8 APPROACH
}

\author{
Antuela A. Tako \\ Stewart Robinson \\ Anastasia Gogi \\ School of Business and Economics \\ Loughborough University \\ Loughborough \\ Leicestershire, LE11 3TU, UK
}

Zoe Radnor

Cass Business School

City, University of London

Northampton Square

London, EC1V OHB, UK

\author{
Cheryl Davenport \\ Leicestershire County Council \\ Championship Way \\ Glenfield \\ Leicester, LE3 8RA, UK
}

\begin{abstract}
This paper introduces a new facilitated simulation approach, called SIMTEGR8, developed to evaluate the effectiveness of integrated community-based health and social care services. This involves developing and using simulation models, which serve as a catalyst for generating discussion about the effectiveness of the patient pathway and for identifying potential improvements to the service. The simulation analyst works jointly with different stakeholder groups: service providers, commissioners, and service users. Service users, a stakeholder group that can contribute to the knowledge generated in facilitated modelling sessions, have not been included in facilitated simulation studies reported so far in the literature. For illustration purposes, the Lightbulb project, a housing support service helping elderly and frail people in Leicestershire in the UK stay safe at home, is presented in this paper. The outcomes of the study and the challenges faced with involving patients in simulation projects are discussed.
\end{abstract}

\section{INTRODUCTION}

The provision of integrated health and social care services is part of a wider UK government initiative to deliver new models of care where local authorities and social care teams work with NHS partners in order to provide joined up and patient-centered services in the community (Charles et al. 2018). This in turn, helps to ultimately reduce emergency hospital admissions. In June 2014, Leicestershire County Council (LCC) responded to this initiative by setting up a "Better Care Together" program, which includes a five year strategic change plan to ensure that Leicestershire offers an integrated health and social care service to its residents (Barber 2015). As part of this program, specialized community-based services were set up to provide care and support to frail and older people. The SIMTEGR8 project was set up in order to evaluate eight pilot services in the Leicestershire area, so that the results of the evaluation would be independently and systematically analysed with academic input. 


\section{Tako, Robinson, Gogi, Radnor, and Davenport}

This paper introduces a new facilitated simulation approach, developed to evaluate the effectiveness of integrated community-based health and social care services in the Leicestershire area as part of the SIMTEGR8 project. SIMTEGR8 stands for Simulation for Great Care and it represents a research collaboration between Loughborough University, Leicestershire County Council (LCC), Healthwatch Leicestershire and SIMUL8 Corp. Computer simulation modelling, more specifically discrete-event simulation (DES), was used in facilitated workshops with groups of stakeholders in order to evaluate selected pilot services, their effectiveness in avoiding emergency admissions, and to assess ways in which the patient journey could be improved. The facilitation process and activities involved are explained. Our aim was to involve both service providers and service users in facilitated DES workshops.

The contribution of this paper is twofold. First, we present a new facilitated DES approach that embeds the perspective of both service providers and service users in the simulation project lifecycle. To the best of our knowledge, this is the first research reported that engages both the client (commissioning body and service providers) and service users (patients and their family) in facilitated DES workshops. Secondly, it demonstrates the potential of using facilitated DES to support and evaluate the effectiveness of communitybased health and social care services. Furthermore, we present a case study as an illustrative example that enables us to reflect on the advantages and limitations of involving various stakeholder groups in facilitated DES interventions.

The paper is structured as follows. Section 2 explores existing literature considering stakeholder involvement and facilitated DES in healthcare. Section 3 presents the SIMTEGR8 approach, followed by an illustrative case study in section 4 , describing the context, the facilitation process, the models developed and the outcomes of using the approach to evaluate the Lightbulb (LB) service. A discussion follows considering the involvement of different stakeholder groups in simulation studies.

\section{STAKEHOLDER INVOLVEMENT AND FACILITATED DES}

Discrete event simulation has been extensively used to model and improve healthcare systems (June et al. 1999; Fone at al. 2003; Brailsford et al. 2009; Paul et al. 2010; Salleh et al. 2017). Reviews of existing healthcare simulation studies identify a limited adoption of findings, suggesting that despite its potential benefits, simulation is not making the intended impact in the healthcare sector (Brailsford 2007; Young et al. 2009; Soorapanth and Young 2018). Jahangirian et al. (2015) note that the lack of communication between simulation modellers and the stakeholder group is a key factor affecting the limited uptake of model outcomes in healthcare. Communication is challenging due to the complex nature of healthcare systems, consisting of multiple stakeholders with distributed power and knowledge (Kotiadis and Tako 2018). In response to this challenge a line of research in facilitated DES has emerged which aims to tackle the need for stakeholder engagement throughout the simulation project lifecycle to ensure that useful and relevant to the stakeholders models are developed (Robinson et al. 2014; Tako and Kotiadis 2015; Baril et al. 2016; Proudlove et al. 2017).

Furthermore, there is currently an increasing interest internationally in involving patients and members of the public in health care research, recognizing the potential benefits that members of the public and service users have to offer in designing and improving health services (Pearson et al. 2013; Monks 2016). In the UK also, health and social care service providers are committed to involving service users and patients in the planning, development and evaluation of their services (Pearson et al. 2013). There was a similar expectation at the time of undertaking the research described in the current paper.

Patient and public involvement (PPI) in healthcare modelling simulation is quite limited (Pearson et al. 2013). They describe two examples where PPI was included in health care modelling projects, primarily as part of defining the modelling objectives and model scope, which informed the models that were subsequently built. Pearson et al 2013 identify a number of benefits from involving service users in the simulation study, including input into obtaining a better understanding of the context and of the objectives to be pursued, design and validation of models from the perspective of the patients and users of these services, as well as identification of acceptable and relevant to patients options for change. 


\section{Tako, Robinson, Gogi, Radnor, and Davenport}

Alongside the benefits, Pearson et al. (2013) recognise the challenges faced when involving lay people and members of the public in technical modelling work such as simulation, which may inhibit modelers to engage more closely with such groups in their work. They discuss the lack of effective communication between researchers and patients to ensure there is shared understanding, primarily due to lack of a common language and knowledge between these groups. For example, patients have a different view of the service, limited to the part of the service they have experience of, which can affect their understanding of the models and technical terms used when considering the service as a whole. Another concern is related to the way patients and service users are identified and selected to participate, to ensure that bias is as much as possible avoided (Pearson et al. 2013). Considering that the user base of health and social care services are elderly and frail people, access and ability to participate is further impaired. Such difficulties were encountered also in the current study.

\subsection{Facilitated DES}

Research on facilitated discrete-event simulation (DES) is gaining momentum, with a number of researchers reporting on building and using DES models in a facilitated mode of engagement with stakeholders. As opposed to the traditional analyst-oriented approach, in this mode the simulation analysts conduct the modelling project jointly with the client in developing models that are not only meaningful and relevant, but that can also support the stakeholder group in identifying feasible solutions (Robinson et al. 2014; Tako and Kotiadis 2015; Kotiadis and Tako 2018). The stakeholder group attends facilitated workshops, where the facilitator guides the process through planned activities of defining the problem, validating the model, considering model findings and identifying possible solutions.

Robinson et al. (2014) developed the SimLean approach that combines the use of simulation models and lean processes to support process improvement in healthcare. They use approximate models to understand the healthcare processes involved and to explore different solutions in facilitated workshops. The authors comment that client engagement enabled the acceptance and implementation of lean improvements identified by the study. Similarly, Baril et al. (2016) combine DES and lean principles to improve patient flows in an outpatient haematology-oncology clinic. Stakeholder involvement varies across the project, between individual and group facilitation to elicit information that informs the models which are created offline. At the end of the project, a Kaizen event was held using simulation-based games live with stakeholders, which informed subsequently the improvements implemented in the clinic.

Tako and Kotiadis 2015 developed PartiSim, a framework that supports the facilitation process in DES, consisting of six stages of which four are facilitated workshops with stakeholders. They also develop tools inspired from Soft Systems Methodology (Checkland 1999) to support the facilitation process and assembly of information in pre-model (Kotiadis et al. 2014) and post-model coding stages (Kotiadis et al. 2018). Proudlove et al. (2017) consider the technical aspect of making the model development phase more facilitated using the Business Process Model and Notation (BPMN) standard to enable stakeholder involvement. They build simulation models of two hospital settings. While the live development of models was possible for a simple model, this was not for more complex models. Further technological extensions to BPMN would be needed, to ensure that more complex models can be built jointly with stakeholders at workshops (Onggo et al. 2018).

Summarising on the above, there are several facilitated DES studies applied in healthcare. While facilitated modelling offers a platform for involving stakeholders in simulation studies, existing studies do not explicitly include service users in the lifecycle of the facilitated DES project.

\section{OVERVIEW OF THE SIMTEGR8 APPROACH}

The SIMTEGR8 approach is a new facilitated simulation approach, which combines two existing approaches, SimLean Facilitate (Robinson et al. 2014) and PartiSim (Tako and Kotiadis 2015), adapted specifically to fit the process carried out to evaluate integrated health and social care services as well as to 
ensure that participation of service provides and users is achieved. The approach enables the triangulation of information between the modelling and the service provider team as well as a group of service users.

\subsection{Team Roles}

The SIMTEGR8 approach recognizes three main stakeholder groups that are involved in the study. The specific roles for each group are presented in Table 1 below. The modelling and service provider team are equivalent to the project and stakeholder team in PartiSim. For more details the reader is referred to (Tako and Kotiadis 2015). We introduce two new roles, which are believed to play an important role in connecting members of the three stakeholder groups: the project manager and the patient voice agency representative.

Table 1: Stakeholder teams and individual roles in the SIMTEGR8 approach.

\begin{tabular}{|c|c|c|}
\hline Modelling team & Service provider team & Service users \\
\hline $\begin{array}{ll}\text { - } & \text { Modeller } \\
\text { - } & \text { Facilitator } \\
\text { - } & \text { Project manager } \\
\text { - } & \text { Note taker } \\
\text { - } & \text { Patient voice agency } \\
& \text { representative }\end{array}$ & $\begin{array}{ll}\text { - } & \text { Project champion } \\
\text { - } & \text { Service manager (key } \\
\text { stakeholder) } \\
\text { - } \\
\text { Other stakeholders } \\
\text { (representing different roles } \\
\text { within the service) }\end{array}$ & $\begin{array}{l}\text { - Patients and carers } \\
\text { (who have used a range } \\
\text { of services) }\end{array}$ \\
\hline
\end{tabular}

The project manager is a member of the modelling team, who acts as a gatekeeper between the modeler and service provider team and ensures that the planned project meetings and workshops take place. The project manager role is different to the project champion role. Similarly to the project champion role in PartiSim (Kotiadis et al 2014), this individual comes from the service provider organization, support the workshops, identifies workshop participants and supports data collection. The project manager role comes from the commissioning body and supports planned project activities, scheduling of workshops and meetings and report writing. A suitable person for this role is someone with very good communication skills and good links with the service provider team. This person can also assume the note taker and/or the facilitator role.

Another key role in SIMTEGR8, is the patient voice agency representative that acts as a gatekeeper between the modelling team and the service users. Their task is to identify relevant members of the service users group (patients and their carers who have experience of the service), invite them to workshops and also to ensure that accessible language at an appropriate level for service users is used at the workshops. A suitable person for this role is a proactive person with very good communication skills and ability to relate well with patients.

\subsection{Key Stages of the SIMTEGR8 Approach}

The approach consists of 5 main stages, of which three are facilitated workshops: project briefing, conceptual modelling workshop (W1), model development, service providers workshop (W2) and service users workshop (W3) (Figure 1). Each stage is next briefly explained.

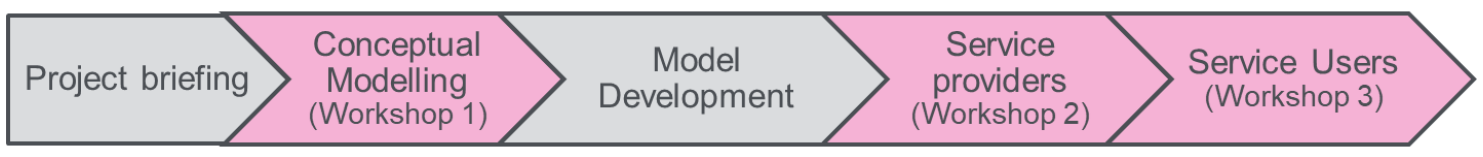

Figure 1: Phases of the SIMTEGR8 approach.

1. Initial Pathway Briefing. This consists of a meeting with a smaller group of stakeholders, including members of the modelling and service provider team. The aim is to develop an initial 
understanding of the pathway, by discussing the aims and priorities of the service, workshop requirements, access to patient representation and data availability to inform the model.

2. Conceptual Modelling Workshop. The stakeholder group discuss the planned pathway and reflect on its efficiency. The discussion serves as a basis for developing the simulated computer model in order to evaluate the intervention. It involves the following four phases:

- Aims of evaluation. A brainstorming session to identify aspects of the service to be evaluated.

- Process map. The modelling and stakeholder group work jointly to identify the main activities that take place in the real system and draw a process map of the service.

- Pathway Effectiveness. A brainstorming session to identify performance measures used by the service. Service users' opinions about their experience are also considered.

- Data Requirements. People responsible for providing the data required are identified, based on the process map developed.

3. Model Development. This is a quantitative representation of the qualitative conceptual diagram developed at the workshop. The detailed complexity of the model is deliberately kept to a minimum to ensure stakeholder and patient participation in the next stages. The model developed provides a sufficient representation of the service to show the basic processes involved, the capacity and use of resources within the system.

4. Service Providers Workshop. This workshop uses the model to facilitate a discussion with members of the service provider team on how the service can be improved. The discussion involves the following four phases:

- Model Understanding. The simulation model developed is presented and shown to the participants to allow them to understand how the simulation works;

- Face Validation. The participants consider whether the simulation model reflects reality;

- Problem Scoping. Based on model results, participants are asked to identify areas that affect pathway effectiveness. Through the model they see an overall view of their process, which can help identify issues that are not obvious in their day-to-day activities as they are normally involved only in their part of the process.

- Improvement. Participants identify changes that can be introduced to the service.

5. Service Users Workshop. The model with improved visual representation is used to help facilitate a discussion with patients and carers. The discussion involves the following three phases4:

- Model understanding. The pathway and model are explained to the participants and the simulation run showing a patient moving around the system.

- Problem Scoping. Issues that have been revealed by running the model and the participants' own experiences and concerns about the service are discussed.

- Improvement. The discussion turns to discussing how the service could be improved.

\section{ILLUSTRATIVE EXAMPLE: THE EVALUATION OF THE LIGHTBULB SERVICE}

\subsection{The Context}

The case study used to illustrate the SIMTEGR8 approach is based on the Lightbulb (LB) service. This is a housing support service helping elderly and frail people in the community to stay safe and longer in their 


\section{Tako, Robinson, Gogi, Radnor, and Davenport}

homes by preventing accidents and falls and keeping them away from hospital. It provides a wide variety of housing support and advice, including minor home alterations, such as hand rail or major home adaptations such as installing a downstairs bathroom or stair lifts. A pilot service was available in some localities within Leicestershire at the time that the project was undertaken (in 2016). Next the key phases of the project and the milestones are briefly explained.

\subsection{Project Briefing}

The modelling team met with the service managers and a patient voice agency representative. It was established that the aim of the LB service evaluation was to support the business case being developed at the time, which involved the design of a new and faster process to deliver services to patients. It quickly became clear that we needed to focus on testing that the new process had been modelled accurately in the business case and that it could deliver the expected time scales and throughput. The existing detailed process map used for the business model was shared with the modeling team. The performance manager in charge of the business case was our main point of contact regarding data requirements for the model.

Stakeholder involvement and the workshops plan was also discussed in this meeting. Analysis of the different roles and staff involved in the LB service took place. As a result the group came up with a list of staff that would be invited to attend the workshops (conceptual modelling and project leads workshop), representing a variety of roles, from those involved in the design of the service, back office support and those providing services to ensure that a good representation of the different aspects of the service was achieved. It was also agreed that service users involvement would be organized by the patient voice agency, in our case Healthwatch, a locally-based independent organization, specializing in making patients' voice heard on aspects related to health and social care. They would oversee the process of communicating with and inviting service users to attend Workshop 3. This also ensured that we were able to adhere to data protection rules and patient confidentiality.

\subsection{Conceptual Modelling Workshop (Workshop 1)}

We held the first workshop with seven key staff from LB, one facilitator, modeller and note taker (project manager) from the modelling team. The workshop was held in a dedicated meeting room. The session was managed within a tight timeframe of $2 \frac{1}{2}$ hours to ensure it impacts minimally on service delivery. The activities that took place are next described.

We started with the aim of the evaluation, which was already discussed at the project briefing meeting. Participants confirmed that the main aims of the service evaluation through the model were: 1) to evaluate the utilization of the staff (occupational therapist - OT, housing support coordinator - HSC, and technical officer - TO) involved in the delivery of the service and distribution of tasks between them; 2) to validate the overall expected times scales in providing services; and 3) to consider the impact of an increase in demand for services. We then spent a significant part of the workshop on drawing the process map. Workshop participants were invited to contribute activities that take place in the service based on their perceptions of the process on a large white paper stuck on a wall. After a few iterations, an agreed process map was produced. This was transferred into a tidied up version on the Visio software after the workshop (Figure 2).

The participants were next invited to identify the metrics used to evaluate the performance of the service. These included: total completion time for minor alterations and major adaptation cases; staff utilisation levels (in \%) and the total number of cases completed by service type and staff type (throughput). The effectiveness of the pathway was then discussed from the project leads' and service users' perspective. This focused on the time taken for services to be provided both from patients' and service providers' point of view. While feedback received from the patients who had used the service during the pilot phase was generally positive, some delays in the time taken to complete the work to be done had been noted. The new redesigned pathway aimed to resolve this. The modelling team was satisfied that the information needed to proceed with building the model was acquired, so the workshop drew to a close. 
Tako, Robinson, Gogi, Radnor, and Davenport

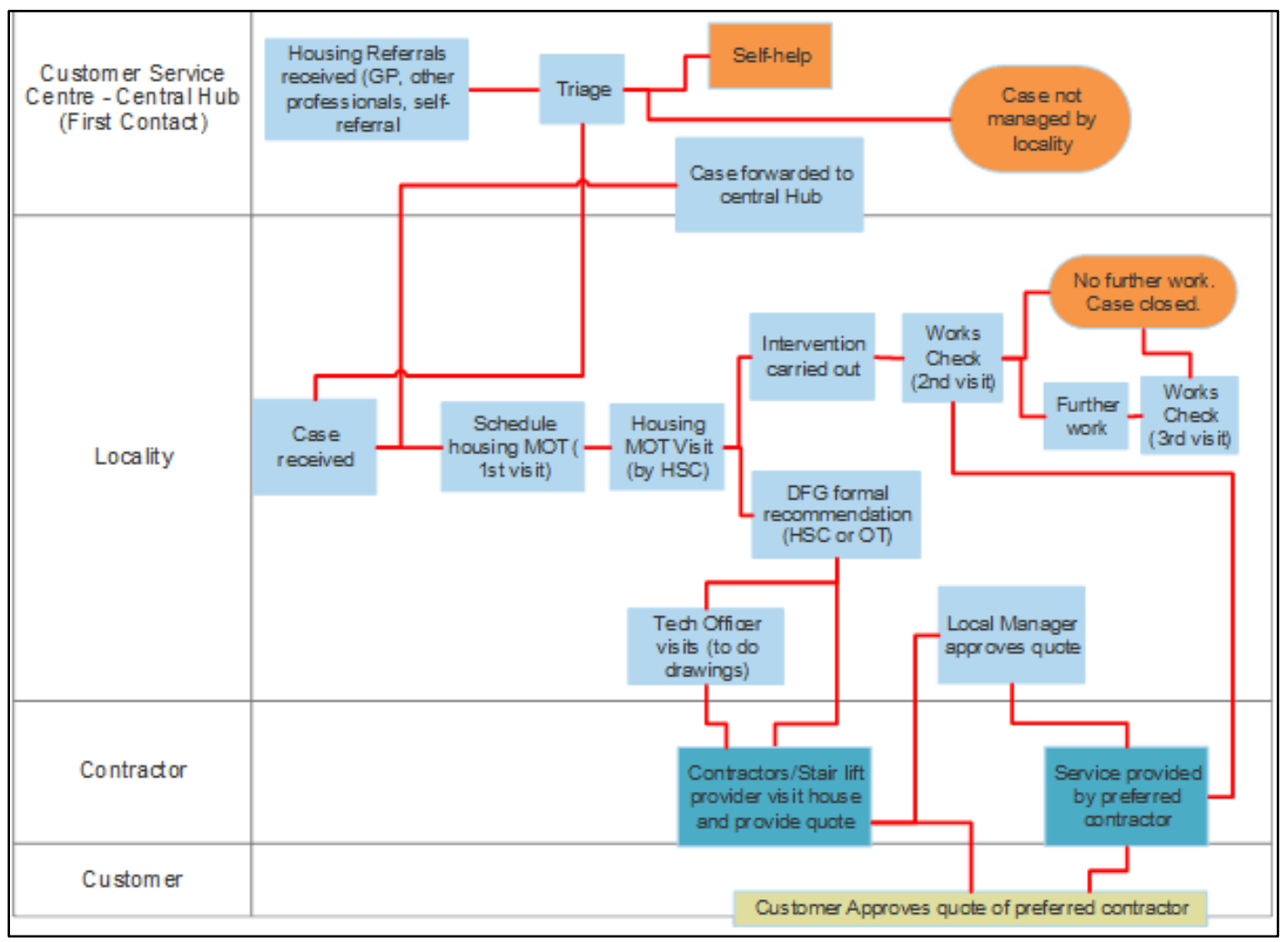

Figure 2: Process map of the Lightbulb service.

\subsection{Model Building}

After the workshop, the conceptual model developed was converted into a simulation model (Figure 3) that imitates the planned flow of services and user cases through the service. The model represents each locality separately as well as the overall Leicestershire service. It shows what each service would look like based on current levels of demand and projected staffing levels in the new redesigned service pathway. The model was also built to allow users to test the customer's journey experience in the case of staff increases and increased demand taking into account population increase in over 65 s by 2020 .

The model outputs include staff utilization for the three types of staff involved in providing services (Housing support coordinator, occupational therapist and technical officers) and the number of cases completed (throughput) by type of service and resource. These were visually displayed in the model (Figure 3) so that participants would be able to validate the model and its outputs at the next workshop.

\subsection{Service Providers Workshop (Workshop 2)}

The workshop was held in a dedicated meeting room. From the modelling team, the facilitator, modeler and the project manager who also was the note taker, were present. There were five members of staff from LB, including the service manager. Two of the participants had not attended the first workshop. The sequence of activities that took place is next briefly described.

The workshop started with an explanation of the model to the participants, including the outputs that it captured (e.g. number of $1^{\text {st }}$ Visits by HSCs, number of Stairlift cases, technical officers total number of cases etc.). The assumptions made were also explained, such as for example that the model did not show interaction with other services. Then the simulation was run through and the participants were allowed time to absorb the model. One specific locality as chosen by the participants, was selected to run the model. 


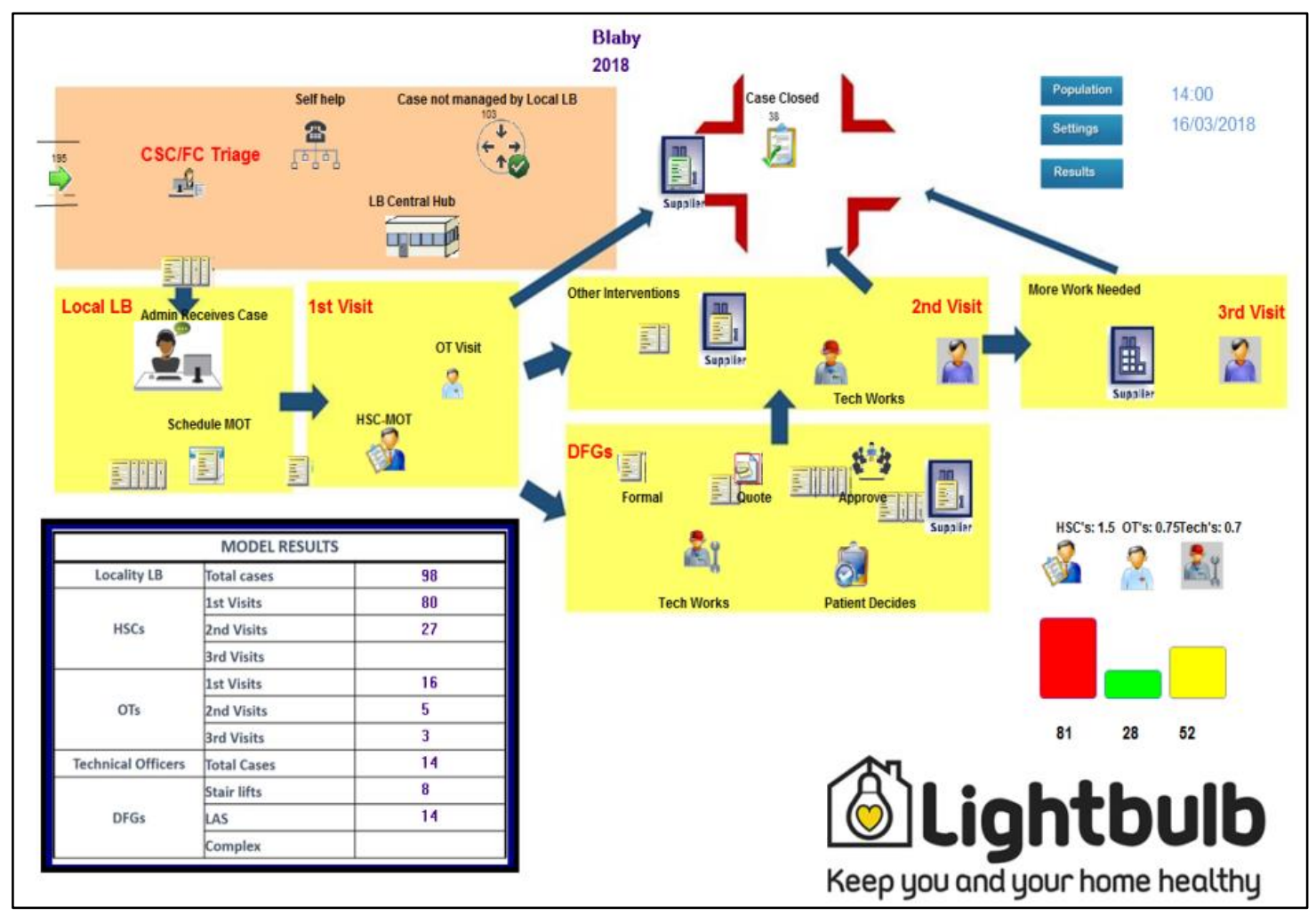

Figure 3: The Lightbulb simulation model.

We were keen to validate the model so the participants were asked to confirm whether the model reflected their understanding of the process. This wasn't intended to be a detailed validation to assess statistical accuracy, but instead for the participants to gain trust in the model, that it was performing as expected. A large part of the workshop was spent on validating the model. A variety of opinions existed within the room and as a result heated discussions took place regarding the data used. This was expected as the model is based on the business case rather than on an established service.

The simulation model outputs show the number of cases for each type of service provided, which matched the metrics used to build the business case, as shown in Table 2. However, it was observed that the model showed that the time taken to complete some of the complex services and major adaptations was longer than it was anticipated. It was agreed that the model would be amended to reflect service times after these data were provided by district council officers.

We then moved on to using the model to evaluate the service and understand the service metrics as provided by the model. Based on the insights gained from the model it was identified that there was a high reliance on HSCs, who were working close to $80 \%$ capacity. Reliance on HSC resulted also in longer case completion and customer waiting times, which were higher than what the service had planned for in the business case. On the other hand, Occupational Therapists and Technical officers were under-utilized, ranging between $29 \%$ - $60 \%$ across the different localities, so it was clear that a further look at the distribution of work in the model was needed.

Reflecting on the model results, the participant group was next encouraged to identify changes that can be introduced to the service. In light of the disproportionate staff utilization levels, it was suggested that HSCs could not work every case through to the end. While there was no time at the workshop to look at this in detail, it was agreed that this would be looked at after the workshop.

Post-workshop, the model was modified to include the changes agreed. The service revisited work flows and division of work amongst staff. Later stages of disabled facilities grants (complex services) were assigned to Technical Officers and Occupational Therapists to complete instead of HSCs. It was also 
suggested that MOT Visits are completed by an Occupational Therapist when all HSCs are busy. Following the workshop, the model was modified to reflect a re-distribution of the work between the staff. The updated model showed a significant reduction in overall case completion and customer waiting times, achieving a reduction between 19\% and 38\% in overall time in the system for disabled grant facilities cases. In addition, more realistic staff workload levels $(60 \%)$ were achieved for all types of staff.

Table 2: Metrics used to build the business case against model results.

\begin{tabular}{|l|l|c|c|}
\hline \multicolumn{2}{|l|}{ Metrics used to build the case } & Business Case Data for Locality 1 & Model results for Locality 1 \\
\hline LB Locality & Total Cases & 810 & 849 \\
\hline \multirow{4}{*}{ HSCs } & 1st Visits & 713 & 761 \\
\cline { 2 - 4 } & 2nd Visits & 178 & 199 \\
\cline { 2 - 4 } & 3rd Visits & 45 & 42 \\
\hline \multirow{4}{*}{ OTs } & 1st Visits & 152 & 161 \\
\cline { 2 - 4 } & 2nd Visits & 38 & 49 \\
\cline { 2 - 4 } & 3rd Visits & 38 & 49 \\
\hline \multirow{3}{*}{ Technical Officers } & Total Cases & 80 & 98 \\
\hline \multirow{3}{*}{ DFGs } & Stair lift & 34 & 28 \\
\cline { 2 - 4 } & LAS & 35 & 54 \\
\cline { 2 - 4 } & Complex & 6 & 5 \\
\hline
\end{tabular}

\subsection{The Service Users Workshop (Workshop 3)}

This workshop was held at a local District Council's offices. The modelling team included a facilitator, the modeler the patient voice agency (Healthwatch Leicestershire). The workshop was attended by nine service users, of which two were carers and two staff members from the LB team (service provider). For reasons that were out of the researchers' control, the service users that attended the workshops had only used the LB service for minor adaptions. Hence, the workshop focused primarily on this part of the service.

The workshop started with a brief explanation of the LB simulation model to the participants. Before the workshop, the model had been further developed into a "User Mode" model. This is a simplified and user-friendly format with improved graphics for the service users. While the model is running, explanatory text appears on screen following the progress of a patient's case through the service. It, furthermore shows only one patient at a time until his/her journey within the service is completed and the simulation stops. This enables us to isolate different types of patients and monitor their journey within the service on a patient by patient basis. To start another patient's journey, users can press the "play" button again.

A Case Study was also handed out to the participants, which explained the pathway of a patient requiring minor adaptations over time. This case was purposely chosen to ensure that the participants relate their experiences to the model. At the same time the simulation model showing the patient journey, described also in the Case Study was run at a relatively slow speed on the screen, with some associated text explaining the different stages of the case appearing on the screen. The participants could watch the patient moving through the parts of the service in the model, while one LB team member explained how this related to the service they had received in real life.

Next, the participants were asked to discuss their experiences with the service and compare it to the model previously presented. This was an indirect way of assessing whether the participants understood the pathway and that it made sense to them, without restricting the discussion to the case presented. The participants commented about the good quality of work delivered by the service and the quick process, the support provided to them, highlighting how it enhanced their quality of life and helped them to be more independent. They also discussed the multi-disciplinary nature of the service, that different services are coordinated by one point of contact, which is considered important as it creates familiarity. Despite the 


\section{Tako, Robinson, Gogi, Radnor, and Davenport}

positives, with encouragement by the facilitator, the participants commented about the fact that the service was not well-known and that there is not enough clarity of the services on offer and how they can be accessed. One of the participants reported that the handyperson assigned was not able to complete the job at one visit and several visits were required by the HSC to ensure that the work was completed.

As the users were generally happy with their experience of completion times, there were no improvements identified that related directly to the patient pathway presented. With encouragement by the facilitator, participants identified a number of possible improvements that the service could benefit from. These were mostly related to improving access to the service, which is expected as the service had been operating on a pilot basis. The service has taken these suggestions on board and better signposting is now provided on the LCC website, with further plans to increase visibility of the service in the community.

\section{REFLECTIONS AND CONCLUSIONS}

We present an example case study where the SIMTEGR8 approach was used to evaluate the LB service, a housing support service based in Leicestershire in the UK. The concept of using a computer simulation of a patient pathway in order to stimulate discussion and to identify ways to improve the service, with members of the service provider and users team, was effective. The discussion that took place in all the three workshops was lively with many contributors. Engagement with the models was high.

The conceptual modelling and service provider workshops achieved a mutual understanding of the service among the participants, this in turn informed the model developed, which was then tested and used to identify further improvements in the service, respectively. Members of the service provider team participated in these workshops. The level of participation between these two workshops differed due to staff's prior commitments. This meant that some of the participants at workshop 2, were not familiar with the discussions that took place in the first workshop. However, based on the participant feedback, the workshops were considered successful and achieved the intended aims. Participants from the service provider team found the workshops useful. At the $2^{\text {nd }}$ workshop, specific refinements to the model were identified. Subsequently the findings of the model were used to inform the design of the LB service. This ensured that expected service times lengths were achievable, which was very important for the service. Furthermore, the LB service continues to use the model as an ongoing tool to plan future changes.

Similarly, based on the feedback collected at the end of the workshop, the service users workshop successfully achieved the aims originally set out. The participants commented that they appreciated the chance to meet and discuss each other's experiences with the service, and to find out more about the service. Participants demonstrated a shared understanding of the pathway, despite having only been involved in a small part of the service. There was some engagement with the simulation model, but less time than anticipated was spent on it. The delegates were quiet and attentive while the simulation model was running on screen; however, some of them looked puzzled. This is expected when presenting a model to lay people and especially those that are frail and elderly. We also noted that the use of acronyms in the model caused some confusion among the participants. The presence of the service staff members at the workshop, helped us to achieve a common level of communication. The participants were familiar with those staff members and a positive rapport had been already established. In the example presented, there were no participants representing all categories of patients that use LB services such as stairlift or level access shower installations. It should be however noted that involving a service user group into a workshop was a great achievement as they face accessibility issues due to their medical condition.

The SIMTEGR8 approach presented in this paper advances the existing practice of facilitated simulation, by developing a new facilitation process that combines the inputs of the modelling team, with that of a group of service providers and users, in using simulation models to inform service improvements. The approach adapts pre-existing facilitated simulation approaches, such as SimLean (Robinson et al. 2014) and PartiSim (Tako and Kotiadis 2015; Kotiadis and Tako 2018) and it includes the key phases of the simulation life cycle: problem formulation, conceptual modelling, model coding, experimentation and model validation. While most of these phases are undertaken in facilitated workshops, working closely with one of the two stakeholder teams (service provider and users), model coding and parts of model validation 


\section{Tako, Robinson, Gogi, Radnor, and Davenport}

and verification are mostly undertaken outside of the workshop by the modeler in what Robinson et al. (2014) call at the back-office.

The SIMTEGR8 modeling team were especially keen to achieve a good level of participation of the different stakeholder groups in the facilitated sessions. This leads us to consider whether a different sequence of activities could work better and/or whether further improvements to the 'User Mode' model layout could improve engagement of service users with the model and ultimately their understanding of how the service works on the whole. Furthermore, as we experienced difficulties in establishing PPI, further software advancements in technology might be needed to engage better with patients and vulnerable groups. Similarly an equivalent participation of the members of the service team in the first two workshops could have avoided some of the disagreements that were aired in the $2^{\text {nd }}$ workshop.

Engagement with service users brought a complementary perspective to the evaluation. It helped the researchers and the evaluation project overall to reach more meaningful conclusions. In this particular case, the participants confirmed that the resulting patient waiting times were acceptable to them. This indirectly confirmed the planned changes regarding the division of tasks among staff that emerged at the end of workshop 2 with the service providers. The service users' input in the case study presented was mostly to confirm our understanding of the context and aims of the evaluation. They did not make a direct input into the model or the data used in it as suggested in Pearson et al. (2013). They however identified complementary suggestions for further improvements to the service, which were not previously obvious to the service provider and modeling team. Service users' involvement in SIMTEGR8 does not necessarily aim to improve the model developed, but to use the model as a vehicle to generate discussion and insights about the service metrics and to identify potential improvements that are acceptable and satisficing to the different stakeholder groups involved.

A new case study is reported where a facilitated approach is used to support the design of communitybased integrated care services, adding to the existing pool of case studies in the facilitated simulation literature. On the whole, our experience of using a computer model of a patient pathway as a vehicle for improvement, change and development has been successful and we invite more researchers to join this exciting field of research.

\section{ACKNOWLEDGMENTS}

We acknowledge the support of the partners in the SIMTEGR8 project, including Leicestershire County Council (LCC), Healthwatch Leicestershire and SIMUL8 Corp. Special thanks go to the Health \& Care Integration Manager at LCC for their input in developing project reports and workshop outputs; the managers and members of the Lightbulb Service as well as the service users and their carers for attending the workshops detailed in this paper, including Blaby District Council.

\section{REFERENCES}

Barber, M. 2015. "Outcomes Roadmap: Anticipated Changes to Health and Social Care Services across Leicester, Leicestershire \& Rutland in Support of the Five Year Strategy" (Version 1, First Issue). Better Care Together. http://www.bettercareleicester.nhs.uk/EasysiteWeb/getresource.axd?AssetID=34600, accessed 9 ${ }^{\text {th }}$ May 2019.

Baril, C., V. Gascon, J. Miller, and N. Côté. 2016. "Use of a Discrete-event Simulation in a Kaizen Event: A Case Study in Healthcare". European Journal of Operational Research 249(1):327-339.

Brailsford, S. C., T. Bolt, C. Connell, J. H. Klein, and B. Patel. 2009. "Stakeholder Engagement in Healthcare Simulation". In Proceedings of the 2009 Winter Simulation Conference, edited by M. D. Rossetti, R. R. Hill, B. Johansson, A. Dunkin and R. G. Ingalls, 1840-1849. Piscataway, New Jersey, USA: Institute of Electrical and Electronics Engineers, Inc..

Brailsford, S. C. 2007. “Advances and Challenges in Healthcare Simulation Modeling: Tutorial”. In Proceedings of the 2007 Winter Simulation Conference, edited by S. G. Henderson, B. Biller, M.-H. Hsieh, J. Shortle, J. D. Tew, and R. R. Barton, 1436-1448. Piscataway, New Jersey, USA: Institute of Electrical and Electronics Engineers, Inc.

Charles, A., C. Ham, B. Baird, H. Alderwick, and L. Bennett. 2018. "Reimagining Community Services: Making the Most of Our Assets”. https://www.kingsfund.org.uk/sites/default/files/2018-01/Reimagining_community_services_report.pdf, accessed $9^{\text {th }}$ May 2019.

Checkland, P. B. 1999. Systems Thinking Systems Practice. Chichester, UK: Wiley. 


\section{Tako, Robinson, Gogi, Radnor, and Davenport}

Fone, D., S. Hollinghurst, M. Temple, A. Round, N. Lester, A. Weightman, K. Roberts, E. Coyle, G. Bevan, and P. Palmer. 2003. "Systematic Review of the Use and Value of Computer Simulation Modelling in Population Health and Health Care Delivery". Journal of Public Health 25(4):325-335.

Jahangirian, M., S.J.E. Taylor, J. Eatock, L.K. Stergioulas, and P.M. Taylor. 2015. "Causal Study of Low Stakeholder Engagement in Healthcare Simulation Projects". Journal of the Operational Research Society 66(3):369-379.

Jun, J.B., S.H. Jacobson, and J.R. Swisher. 1999. "Application of Discrete-event Simulation in Health Care Clinics: A Survey". Journal of the Operational Research Society 50(2): 109-123.

Kotiadis, K. and A.A. Tako. 2018. "Facilitated Post-model Coding in Discrete Event Simulation (DES): A Case Study in Healthcare", European Journal of Operational Research, 266:3, 1120-1133.

Kotiadis, K., A.A. Tako and, C. Vasilakis. 2014. "A Participative and Facilitative Conceptual Modelling Framework for Discrete Event Simulation Studies in Healthcare", Journal of the Operational Research Society, 65(2): 197-213.

Monks, T. 2016. "Operational Research as Implementation Science: Definitions, Challenges and Research Priorities", Implementation Science, 11:81.

Onggo B.S.S., N.C. Proudlove, D’Ambrogio, S. A. Calabrese, B. Stefania, and N. L. Ghiron. 2018. “A BPMN Extension to Support Discrete-event Simulation for Healthcare Applications: An Explicit Representation of Queues, Attributes and Data-driven Decision Points", Journal of the Operational Research Society, 69:5, 788-802.

Paul, S.A., M.C. Reddy, and C.J. DeFlitch. 2010. "A Systematic Review of Simulation Studies Investigating Emergency Department Overcrowding”, Simulation, 86 (8-9) p. 559-571.

Pearson, M., T. Monks, A. Gibson, S. Brailsford, and K. Stein. 2013. "Involving Patients and the Public in Healthcare Operational Research-The Challenges and Opportunities", Operations Research for Health Care, 2:86-89.

Proudlove N.C., S. Bisogno, B.S.S. Onggo, A. Calabrese, and N.L. Ghiron. 2017. "Towards Fully-facilitated Discrete-event Simulation Modelling: Addressing the Model Coding Stage", European Journal of Operational Research, 263, (2):583-595.

Robinson, S., C.Worthington, N. Burgess, and Z.J. Radnor. 2014. "Facilitated Modelling with Discrete-event Simulation: Reality or Myth?", European Journal of Operational Research, 234 (1): 231-240.

Soorapanth, S. and T. Young. 2018. "Assessing the Value of Modelling and Simulation in Health Care: An Example Based on Increasing Access to Stroke Treatment". Journal of the Operational Research Society 70(2): 226-236.

Tako A.A. and K. Kotiadis. 2015. "PartiSim: A Framework for Participative Simulation Modelling", European Journal of Operational Research, 244 (2): 555-564. DOI: 10.1016/j.ejor.2015.01.046.

Young, T., J. Eatock, M. Jahangirian, A. Naseer, and R. Lilford. 2009. "Three Critical Challenges for Modelling and Simulation in Healthcare". In Proceedings of the 2009 Winter Simulation Conference, edited by M.D. Rossetti, R.R. Hill, B. Johansson, A. Dunkin, and R.G. Ingalls, 1823-1830. Piscataway, New Jersey: Institute of Electrical and Electronics Engineers, Inc.

\section{AUTHOR BIOGRAPHIES}

ANTUELA A. TAKO is a Reader in Operational Research at the School of Business and Economics, Loughborough University. She holds a PhD in Simulation and an MSc in Management Science and Operational Research from the University of Warwick. Her research interests include comparison of simulation approaches, facilitated and participative simulation modelling, conceptual modelling and health care modeling. Antuela is an Associate Editor of the Journal of the Operational Research Society and Journal of Simulation. Her email address is a.takou@lboro.ac.uk.

STEWART ROBINSON is Professor of Management Science and Dean at the School of Business and Economics, Loughborough University, UK. He holds an honors degree in Management Science (Operational Research) (1985) and a PhD in Management Science (1998), both from Lancaster University. His research interests are in the practices and use of simulation models where he focuses on conceptual modelling, model validation, output analysis and alternative simulation methods (discrete-event, system dynamics and agent based). His email address is s.l.robinson@1boro.ac.uk, and his home page is www.stewartrobinson.co.uk.

ANASTASIA GOGI was the Research Associate in the SIMTEGR8 project. Anastasia holds a BSc in Industrial Management (University of Piraeus, Greece), an MSc in Management Sciences (University of Southampton, UK) and a PhD (Loughborough University, UK). Her research intersts include behavioural OR and simulation. Her email address is anagogis@gmail.com.

ZOE RADNOR is Professor of Service Operations Management at Cass Business School and VP of Strategy and Planning for City, University of London. Zoe holds a PhD in Management Science from the University of Manchester, UK, an MSc in MSc in Computer Integrated Manufacturing, Cranfield University, UK and a BEng (Hons) in Production Engineering and Production Management, University of Nottingham, UK. Zoe's research interest is in performance and process improvement and service management within public sector organisations. She is a Fellow of the British Academy of Management (FBAM) and the Academy of Social Science (FAcSS). Her e-mail address is zoe.radnor@city.ac.uk.

CHERYL DAVENPORT is Director of Health and Care Integration at the Leicestershire County Council. Cheryl has 27 years' experience of working in health and care in the UK. Her email address is: Cheryl.Davenport@leics.gov.uk. 